\title{
Utilization of Lignin from the Waste of Bioethanol Production as a Mortar Additive
}

\author{
By: \\ Faizatul Falah*, Muhammad Adly Rahandi Lubis, Triastuti, Widya Fatriasari, \\ Fahriya Puspita Sari
}

Research Center for Biomaterials, Indonesian Institute of Sciences. Cibinong16911, West Java, Indonesia

*E-mail: fayzaa_falah@yahoo.com

\begin{abstract}
Lignin is the second most abundant biopolymer, exceeded only by cellulose, and comprises 15$25 \%$ of the dry weight of woody plants, with around 285,000 tons/year of production capacity globally. This study aims to utilize the lignin obtained from the waste of bioethanol production from oil palm empty fruit bunches (OPEFB) as a mortar additive. The use of mortar as a material for road construction is increasing, but its long time hardening is causing problems such as traffic jams. Lignin can be used as an additive to shorten the hardening time of mortar. Lignin was isolated at various NaOH concentrations and temperatures of OPEFB pretreatment for bioethanol production. The workability of the slump and compressive strength of mortars generated were further tested. Lignin from OPEFB can be used as a water reducer in the mortar with improved workability as much as $24.4 \%$ compared to controls. The addition of lignin could also increase the compressive strength at the mortar age of 7 and 28 days compared to the commercial lignosulfonate and control on the various water-cement ratios. The setting time of mortar with the lignin addition increased rapidly, reaching up to $80 \%$ at the 7 days, indicating that curing time is getting shorter. The most remarkable improvement of compressive strength with suitable workability and high-quality concrete was reached by $1 \%$ lignin addition and 0.45 water-cement ratio with compressive strength $38.81 \mathrm{~N} / \mathrm{mm}^{2}$ at 28 days.
\end{abstract}

Keywords: compressive strength, lignin, mortar, OPEFB, water reducer

\section{INTRODUCTION}

Lignin is present naturally in lignocellulosic plants accounting for approximately 300 billion tonnes globally (Dessbesell et al. 2020). Around 100 million tonnes per year are technical lignins, primarily coming from the pulp and paper industry (FAO 2019). Technical lignin can be defined as a form of lignin isolated after a series of biomass processing stages. Types of technical lignin vary mainly in molecular weight and structure, essentially determining the routes for lignin valorization and application (Hermiati et al. 2017; Natarelli et al. 2019). Pretreatment of lignocellulosic biomass is a stage that cost many and greatly affects the overall cost of bioethanol production (Zhang et al. 2013). The purpose of pretreatment is to open the lignocellulosic structure of cellulose to become more accessible to the enzymes that break down the polysaccharide polymer into monomeric sugars. This pretreatment can be done with an acid or alkaline or with steam (steam explosion). Some wastes that contain lignin are generated as the results of pretreatment (delignification process).

The lignin-containing wastewater is usually burned to provide heat and electricity in the process. The rest is sold as a byproduct for fuel or as a mixture or binder in animal feed (Windeisen and Wegener 2012; Yang et al. 2015; Zhang et al. 2013). One attempt to make use of lignin-containing wastewater is to use it as a wood adhesive or reacting it with bisulfite to 
produce a lignosulfonate compound that is widely known as an additive in cement, fertilizer, paper coating, and others (Angelini et al. 2019; Aro and Fatehi 2017; Hemmilä et al. 2019). Thus the bioethanol production process from lignocellulosic materials is expected to produce minimal waste (zero waste) as the wastes are also processed further not to pollute the environment. In addition, the processing of lignin into more value-added material is expected to add economic value to the bioethanol production process from lignocellulosic materials that ultimately can lower the cost of bioethanol production (Sudiyani et al. 2013).

Since the 20th century, mortar has been made by mixing Portland cement and sand (ASTM C 270, 1992). Mortar is defined as a mixture of cement, sand, and water, which is the main adhesive in the concrete mixture. In addition to concrete mixtures, mortar is also used as a plaster in bricklaying which functions as an adhesive to glue bricks together into a strong and rigid unit, as a coating for walls, ceilings, and other repair materials. Some of the properties reviewed in the mortar manufacture are compressive strength, tensile strength, water absorption, and density. The appropriate composition of mortar for plastering is cement: sand $=1: 3$ to 1: 4. If required, several admixtures in the right dosage can be added to increase some mortar properties. Mortar tests are carried out according to ASTM C91 and C270 and SNI 031972-1990 and 03-1974-1990.

The use of mortar and concrete in road construction has been increasing to replace the asphalt road. This is because mortar and concrete have several advantages over asphalt which can withstand heavy loading vehicles, resistant to flooding, low maintenance cost, and can be used on weak soil structure without the need to improve the soil structure (Jankowska et al. 2018; Zheng et al. 2018). However, the time required for the mortar and concrete's hardening causes trouble, such as traffic jams. Some additives that can increase the compressive strength and shorten the hardening time of mortar and concrete produced is then required. Methods of improving mortar's strength, durability, and flow-properties for better workability are constantly under research (Childs et al. 2019; Gupta et al. 2017; Jankowska et al. 2018; Zheng et al. 2018). Plasticizers, such as water-soluble lignosulfonates, are often added into the concrete mixture to disperse cement particles to enhance flow-properties while using low water contents (Childs et al. 2019; Gupta et al. 2017)

Lignin consists of molecules of polyphenol compounds that serve as a binding of cells to each other so that it becomes stiff and rigid, but it can reduce its mechanical strength (Tribot et al. 2019). Therefore, lignin can be used as adhesive in plywood, composites, and lignosulfonate (Angelini et al. 2019; Aro and Fatehi 2017; Hemmilä et al. 2019). Lignosulfonate is one of the lignin derivative obtained by sulfonation of lignin, a water-soluble polymer polyelectrolytes. Lignosulfonate is obtained from the black liquor derived from pulp mill effluent, both of which use the Kraft pulping and other processes such as sulfite and others (Dessbesell et al. 2020).

Lignin from the waste of bioethanol production is proposed as an alternative of technical lignin from the pulp and paper industry, which is harvested from plantation forest or secondary forest. It is estimated by 2030, around 225 million tonnes of lignin is produced per year as a byproduct of bioethanol production since the Renewable Fuel Standard Program has mandated the production of 60 billion gallons of bioethanol (Wang et al. 2019). GreenValue SA, Alpnach Dorf, Switzerland, is one of the industries that have pilot facilities for lignin recovery, particularly from bioethanol production (Kalliola et al. 2015). The resulting sulfur-free lignin has been used as a bio-based plasticizer via alkali- $\mathrm{O}_{2}$ oxidation. The oxidized lignin can be used as a plasticizer for cement pastes, mortar, and concrete. The addition of lignin into the mortar as a plasticizer to reduce the required amount of water has a weakness in the hydration, such as the length of time required for the mortar setting (Kalliola et al. 2015).

As a plasticizer, lignosulfonate can reduce the water, and enhance the workability and maintain slump, thus the mixture of concrete and cement can be formed preferably without adding too much water and reduce the energy required to dry the cement (Nadif et al. 2002). 
This can occur due to lignosulfonate's addition in the cement alters the initial spacing and degree of layering of the tobermorite gel which takes place on the first drying. This change of structure facilitates increased drying shrinkage by increasing the number of sites available for the egress of interlayer water, and by increasing the interlayer space or solid volume in the hydrated paste structure (Lin and Meyer 2009). In addition, the synthesis of lignosulfonate by lignin sulfonation requires a series of production processes and eventually increases the production costs (Aro and Fatehi 2017). Therefore, it is necessary to modify the lignosulfonate by directly mixing the precipitated lignin from the pretreatment stage of bioethanol production into the mortar to speed up the hardening time. This study aimed to utilize lignin-containing wastewater obtained from the pretreatment of empty palm fruit bunch fibers in bioethanol production as a lignin source for mortar additive, which could act as a water reducer and to increase the compressive strength of mortar.

\section{MATERIALS AND METHODS}

\section{Materials}

Oil palm empty palm fruit bunch (OPEFB) was obtained from PTPN VIII, Malingping, Banten, Indonesia. OPEFB fibers were prepared by washing, drying, and grinding to a powder of \pm 30 mesh. Analysis of lignin content, extractives, cellulose, and hemicellulose was done according to TAPPI T222 and TAPPI T203 (TAPPI 1999, 2002). Commercial lignosulfonate (NaLS) was supplied from PT. Ligno Specialty Chemicals (Tangerang, Banten). Portland cement, sand, and water were used to prepare the mortar. The sand was screened to pass a 150 mesh and retained 4 mesh before use. The sand was then filtered and dried by heating it under sunlight.

\section{Isolation and Characterization of Lignin and Lignosulfonate}

Pretreatment of OPEFB fibers was performed with various $\mathrm{NaOH}$ concentrations as the solvent $(10,15$, and $20 \%)$ and various cooking temperatures $\left(150,160\right.$, and $\left.170^{\circ} \mathrm{C}\right)$ in a rotary digester to separate the lignin from the cellulose and hemicellulose. The lignin-containing wastewater was separated from the residue using a wire cloth screen. Lignin was obtained using technical lignin via acid precipitation. Lignin isolation was done by adding $2 \mathrm{~N} \mathrm{H}_{2} \mathrm{SO}_{4}$ and 0.1 $\mathrm{N} \mathrm{NaOH}$ to obtain a precipitate of lignin. Lignin isolates and commercial NaLS were scanned using Fourier Transform Infrared Spectroscopy (FTIR, Shimadzu, Japan) from $400 \mathrm{~cm}^{-1}$ to $4000 \mathrm{~cm}^{-1}$ at room temperature.

\section{Preparation of Mortar and Mixing with Additive}

Sand and cement are mixed with the ratio of $2: 1$. Water was added to get water-cement ratio (W/C ratio) of $0.425 ; 0.45 ; 0.475$ and 0.50 . Sand and cement are mixed in a mixer for 3 minutes. Different contents of lignin and NaLS were added into the mixture, such as 0,1 , and $2 \%$, and around $5 \%$ of $\mathrm{CaCl}_{2}$ was appended as well. The mixture was stirred again for 1 minute. The workability of the resulting mortar was analyzed to determine the performance of the water reducer. The fresh mortar was poured into a cylindrical mold with a $50 \mathrm{~mm}$ height and a $25 \mathrm{~mm}$ diameter in 3 layers. Specimens of mortar were removed from the mould after 24 hours. The specimens were then immersed in water during the curing time ( 7 and 28 days) and drained at room temperature a day before testing. Prior to analysis, each mortar specimen was weighed, and the diameter and height were measured. 


\section{Evaluation of Mortar Properties}

The mortar's slump value or workability test was done using the Slump and Flow Table Test CN-160 (Thaker and Arora 2015). The compressive strength of specimens was tested by Universal Testing Machine (UTM, Shimadzu, Japan) with a maximum loading capacity of 50 $\mathrm{kN}$. The compressive strength test method was done according to SNI 03-1974-1990 (BSN 1990). Implementation of the testing was performed on the specimen age of 7 and 28 days.

\section{RESULTS AND DISCUSSION}

\section{Properties of lignin and lignosulfonate}

The summary of chemical analysis results in OPEFB fibers as the raw material can be seen in Table 1. The highest yield of lignin was obtained at a cooking temperature of $160^{\circ} \mathrm{C}$ and $20 \%$ of $\mathrm{NaOH}$ concentration (Figure 1). This is presumably due to these operating conditions was where the best delignification process, in which the ester bond between the $\mathrm{NaOH}$ damaging lignin, hemicellulose, and cellulose and lignin dissolved in the $\mathrm{NaOH}$ in the greatest amount (Hermiati et al. 2017). At a temperature of $170^{\circ} \mathrm{C}$, the yield of lignin increased in large quantities by increasing concentrations of $\mathrm{NaOH}$. However, its yield at a $10 \%$ concentration is much smaller than its yield at a temperature of $160^{\circ} \mathrm{C}$ and the same concentration. The lignin yield at a temperature of $170^{\circ} \mathrm{C}$ concentrations of 15 and $20 \%$ did not differ much with the lignin yield at a temperature of $160^{\circ} \mathrm{C}$ with the same concentration. Increased delignification temperatures require more power so that the process at a temperature of $160^{\circ} \mathrm{C}$ is better because with fewer resources, the yield of lignin produced was relatively similar to the yield at a temperature of $170^{\circ} \mathrm{C}$.

Table 1. Chemical analysis of OPEFB fibers.

\begin{tabular}{clcc}
\hline No & Component & Content (\%) & Standard Deviation \\
\hline 1 & Extractives & 3.21 & 0.02 \\
2 & Lignin & 26.82 & 1.22 \\
3 & Holocellulose & 69.90 & 0.65 \\
4 & Alpha cellulose & 29.86 & 0.53 \\
5 & Hemicellulose & 24.58 & 0.11 \\
\hline
\end{tabular}

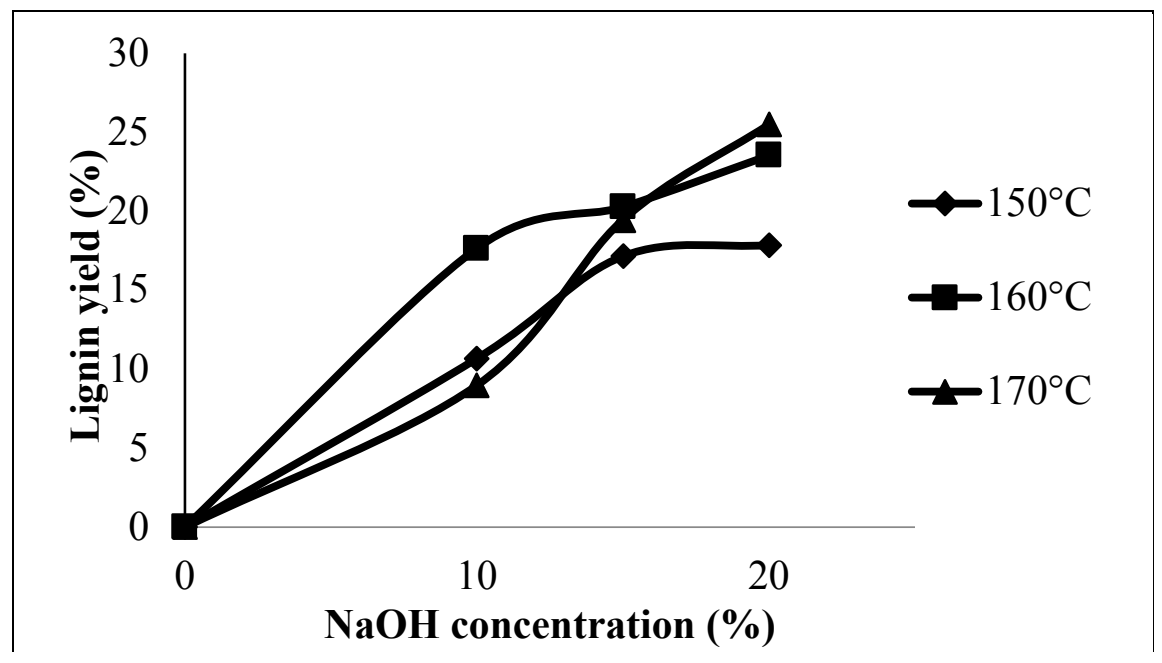

Figure 1. Lignin yield on various temperatures. 


\section{FTIR Analysis of Lignin}

In order to determine which process conditions are suitable to produce lignin with optimum results, lignin obtained from the precipitate was analyzed by using FTIR. As depicted in Figure 2, the FTIR spectra of lignins from various $\mathrm{NaOH}$ concentrations and temperatures showed that the type of lignin group produced was more influenced by the operating temperature of delignification than by the concentration. The concentration of $\mathrm{NaOH}$ used in cooking much affects the content of groups in lignin. FTIR spectra of lignin obtained at the cooking temperature of $150^{\circ} \mathrm{C}$ showed that $\mathrm{NaOH}$ concentration used in the cooking solution did not affect the concentration and carbon clusters produced in lignin obtained (Figure 2a). The increase in $\mathrm{NaOH}$ concentration used did not increase concentrations of carbon clusters generated in the lignin. This is because at a temperature of $150^{\circ} \mathrm{C}$, the degradation of cell wall structure by $\mathrm{NaOH}$ was just started so that the amount of lignin dissolved did not increase significantly even if the concentration of $\mathrm{NaOH}$ increased so that only a small amount of lignin dissolved in $\mathrm{NaOH}$ (Aro and Fatehi 2017).
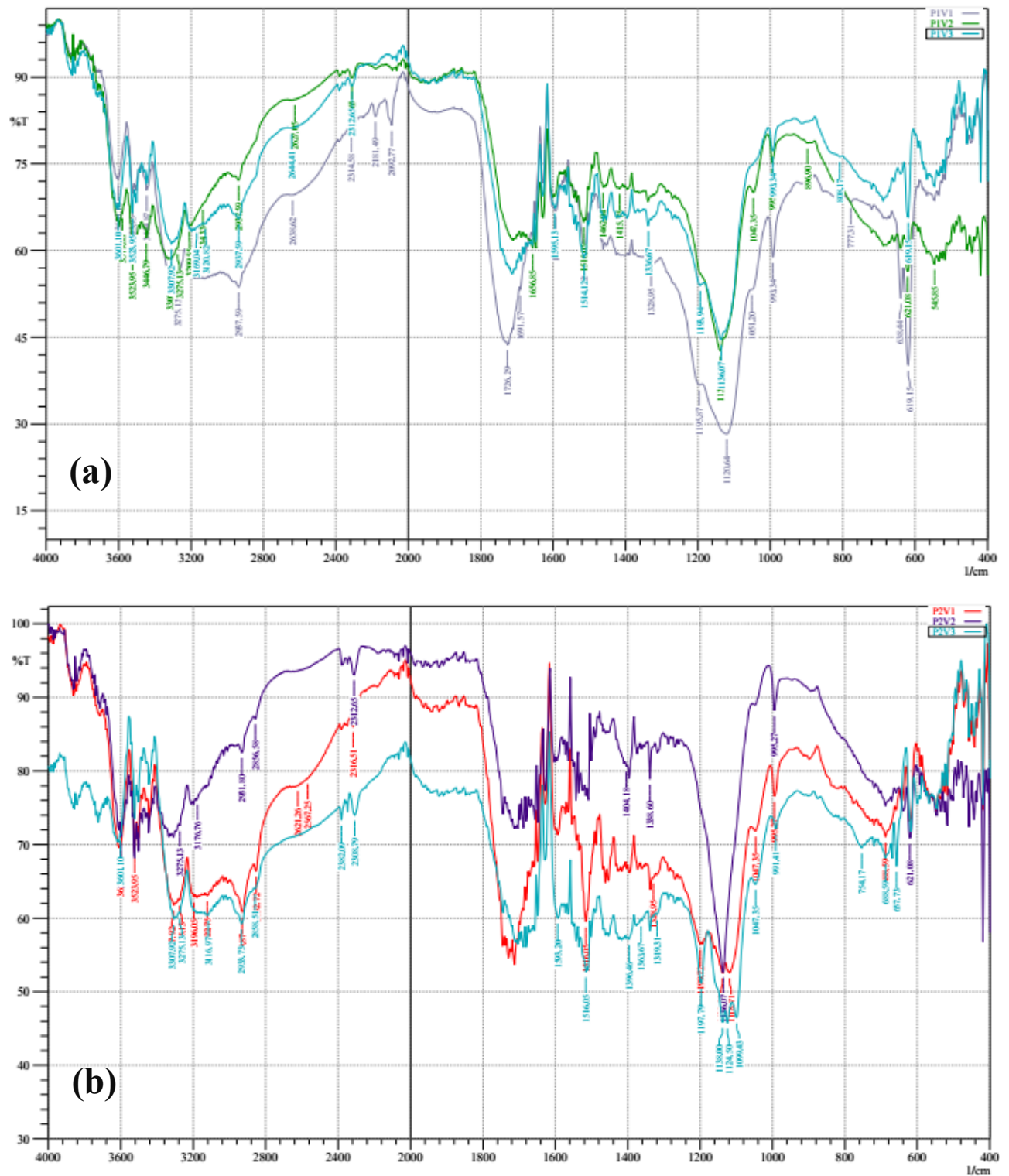

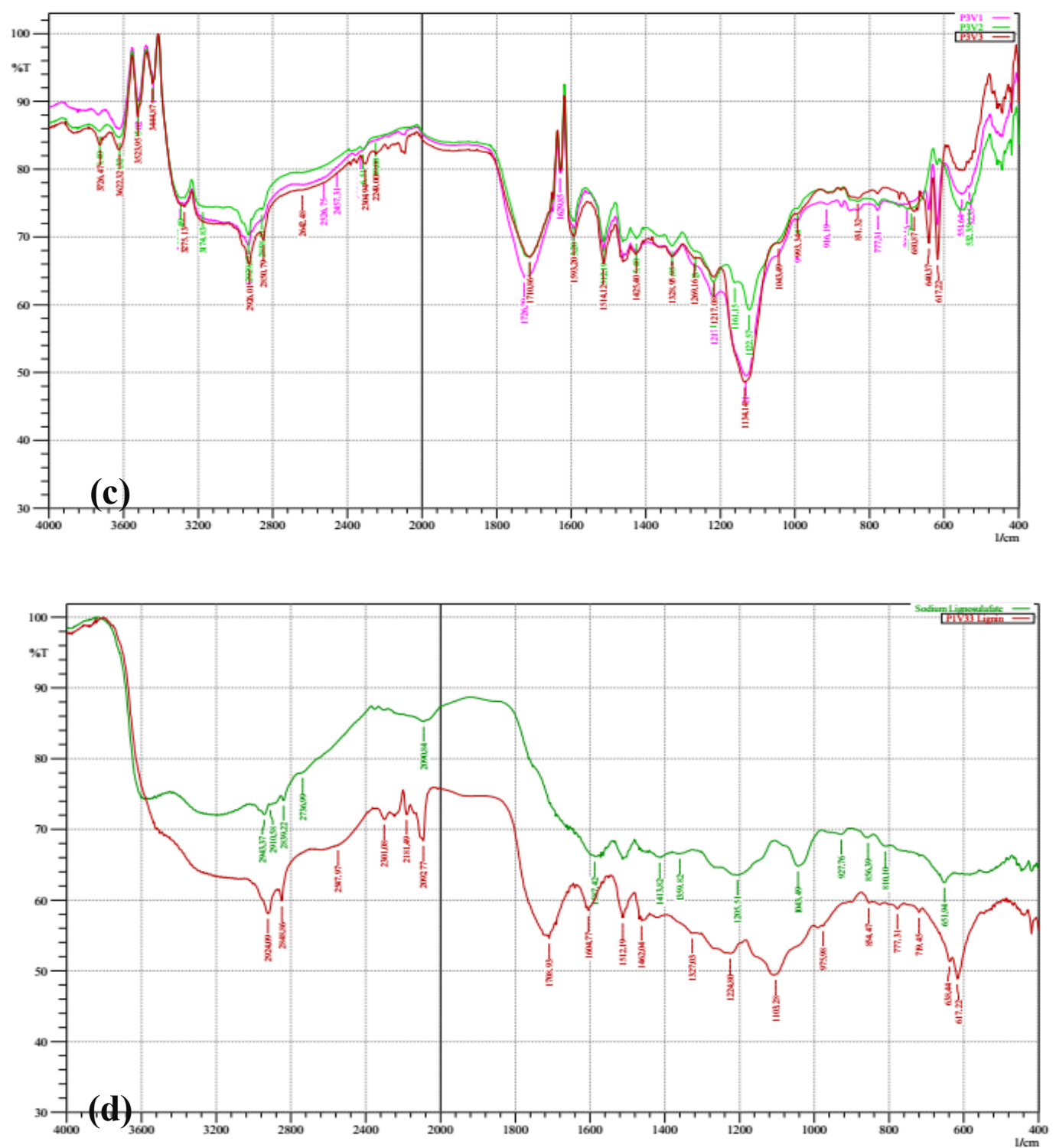

Figure 2. FTIR analysis of lignin generated at $10-20 \%$ of $\mathrm{NaOH}$ and temperatures of

a. $150^{\circ} \mathrm{C}$, b. $160^{\circ} \mathrm{C}$, c. $170^{\circ} \mathrm{C}$, and d. Overlay images of $\mathrm{NaLS}$ and lignin obtained at $160^{\circ} \mathrm{C}$ and $20 \%$ of $\mathrm{NaOH}$.

Moreover, Figure $2 \mathrm{~b}$ shows that the concentration of cooking solution at the cooking temperature of $160^{\circ} \mathrm{C}$ affects the resulting lignin concentration obtained. The absorbance increased by the increasing concentration of $\mathrm{NaOH}$ from $10 \%$ to $20 \%$, indicating the growing concentration of carbonyl groups present in the lignin. The only differences were the lignin concentration. Figure $2 \mathrm{c}$ displays the FTIR of lignin obtained by the cooking temperature of $170^{\circ} \mathrm{C}$. The concentration of a cooking solution affects the concentration and carbon groups produced in lignin obtained. The increasing concentration of $\mathrm{NaOH}$ increased the absorbance of lignin obtained, indicating the growing concentration of carbonyl groups present in the lignin. Increasing operating temperature to $170^{\circ} \mathrm{C}$ gave the largest yield differences on various lignin concentration but with different carbon groups structures on the results. This is presumably due to the increasing degradation of cell wall structure by $\mathrm{NaOH}$ at a temperature of $170^{\circ} \mathrm{C}$ that resulted in different carbon groups at each concentration of $\mathrm{NaOH}$ used (Aro and Fatehi 2017). 
The overlay FTIR spectra of lignin obtained from OPEFB fibers cooked with a temperature of $160^{\circ} \mathrm{C}$ at a concentration of $20 \% \mathrm{NaOH}$ was similar to that on commercial $\mathrm{Na}$ lignosulfonate (NaLS). According to the spectra, commercial NaLS and lignin from waste OPEFB fibers showed the difference in the absorbance's sharpness. Lignin from OPEFB fibers was larger than the commercial ones (Aro and Fatehi 2017). This is probably due to the number of organic groups in the lignin was more than on the NaLS. From the lignin yield and FTIR analysis, the optimum operating conditions selected to produce the best lignin is at a temperature of $160^{\circ} \mathrm{C}$ and $20 \% \mathrm{NaOH}$ concentration. The peak at $3300-3400 \mathrm{~cm}^{-1}$ was assigned to $-\mathrm{OH}$ stretching vibration. Peaks around 2935 and $2840 \mathrm{~cm}^{-1}$ were attributed to $\mathrm{C}-\mathrm{H}$ of methyl and methylene and $-\mathrm{CH}_{3}$ vibration, respectively. The main difference was at around $1720 \mathrm{~cm}^{-1}$ which was assigned to $\mathrm{C}=\mathrm{O}$ vibration from lignin. Other peaks were similar between commercial NaLS and the isolated lignin (Aro and Fatehi 2017).

\section{Application of lignin-based additive on mortar}

\section{Effect of Additives on Slump value}

The effects of additives on mortar were analyzed by the Flow Table Test. Table 2 presents the slump values of mortar with additives by measuring its liquid/solid stage. The workability/slump value test was done by pouring the mortar into the mold with 2 times of compaction, let it for 90 seconds, then lift the mold, and stroke the flow table by turning the handle as much as 25 times for 15 seconds. The slump test value is calculated by measuring the mortar's average diameter at the 4 positions (Thaker and Arora 2015).

Tabel 2. Slump value of mortar with additives.

\begin{tabular}{|c|c|c|c|c|c|c|c|c|c|}
\hline \multirow{2}{*}{$\begin{array}{l}\text { Mortar } \\
\text { additive }\end{array}$} & \multirow{2}{*}{$\begin{array}{l}\text { Water } \\
\text { Reducer }\end{array}$} & \multicolumn{8}{|c|}{ Slump value (mm) } \\
\hline & & $\begin{array}{c}\mathrm{W} / \mathrm{C} \\
0.425\end{array}$ & IM (\%) & $\begin{array}{l}\mathrm{W} / \mathrm{C} \\
0.45\end{array}$ & $\operatorname{IM}(\%)$ & $\begin{array}{c}\mathrm{W} / \mathrm{C} \\
0.475\end{array}$ & $\operatorname{IM}(\%)$ & $\begin{array}{l}\mathrm{W} / \mathrm{C} \\
0.50\end{array}$ & $\operatorname{IM}(\%)$ \\
\hline \multirow[t]{3}{*}{$\mathrm{NaLS}$} & NaLS $0 \%$ & 102.0 & - & 105.3 & - & 113.3 & - & 135.0 & - \\
\hline & NaLS $1 \%$ & 102.3 & 0.3 & 124.5 & 18.3 & 155.5 & 37.3 & 175.8 & 30.2 \\
\hline & NaLS $2 \%$ & 129.5 & 27.0 & 132.3 & 25.7 & 166.5 & 47.0 & 182.8 & 35.4 \\
\hline \multirow[t]{3}{*}{ Lignin } & Lignin $0 \%$ & 102.8 & 0.7 & 105.3 & - & 113.3 & - & 135.0 & - \\
\hline & Lignin 1\% & 105.5 & 3.4 & 111.8 & 6.2 & 133.0 & 17.4 & 146.3 & 8.3 \\
\hline & Lignin 2\% & 106.5 & 4.4 & 114.3 & 8.6 & 139.5 & 23.2 & 168.0 & 24.4 \\
\hline
\end{tabular}

Note: IM = percentage of improvement.

Figure 3 shows that lignin obtained from OPEFB fibers served as a water reducer. The workability increased to $24.4 \%$ (on a W/C 0.5 ) compared to mortar control with no addition of water reducer. The resulting mortar slump values meet the requirements demanded by a Flow Table-type CN-160 a minimum of $110 \mathrm{~mm}$ with a $10 \%$ tolerance, especially on the W/C of 0.45 or more (Table 2). Figure 3 also showed that the use of both lignin and NaLS could reduce the need for water used. The $\mathrm{W} / \mathrm{C}$ required to meet the requirements of a good slump was 0.45 with the addition of additives, compared to the mortar without additives that require $\mathrm{W} / \mathrm{C}$ of 0.475 . An increase in the slump value of mortar with lignin from waste OPEFB fibers was lower than that on NaLS where the value can reach an increase of $47.0 \%$ compared to the control at W/C 0.475. This is probably due to the differences in hydrophilic groups of lignin and NaLS, affecting its ability to enlarge the pore distribution and dispersing the cement and liquid. The improvement of water reducing ability in mortar slump was influenced by its ability to enhance 
the surface adsorption and particle dispersion. When lignin or lignosulfonate that works as a surfactant is added to the mortar, the particles of surfactant adsorption occurs on the surface of cement particles and causing repulsion between the particles of cement which produces strong deflocculation that cause an inhomogeneous distribution of cement particles in the mixture (Takahashi et al. 2014). In this case, lignosulfonate hydrophilicity was better than lignin from OPEFB fibers so its ability to disperse the fluid and cement particles was also greater.

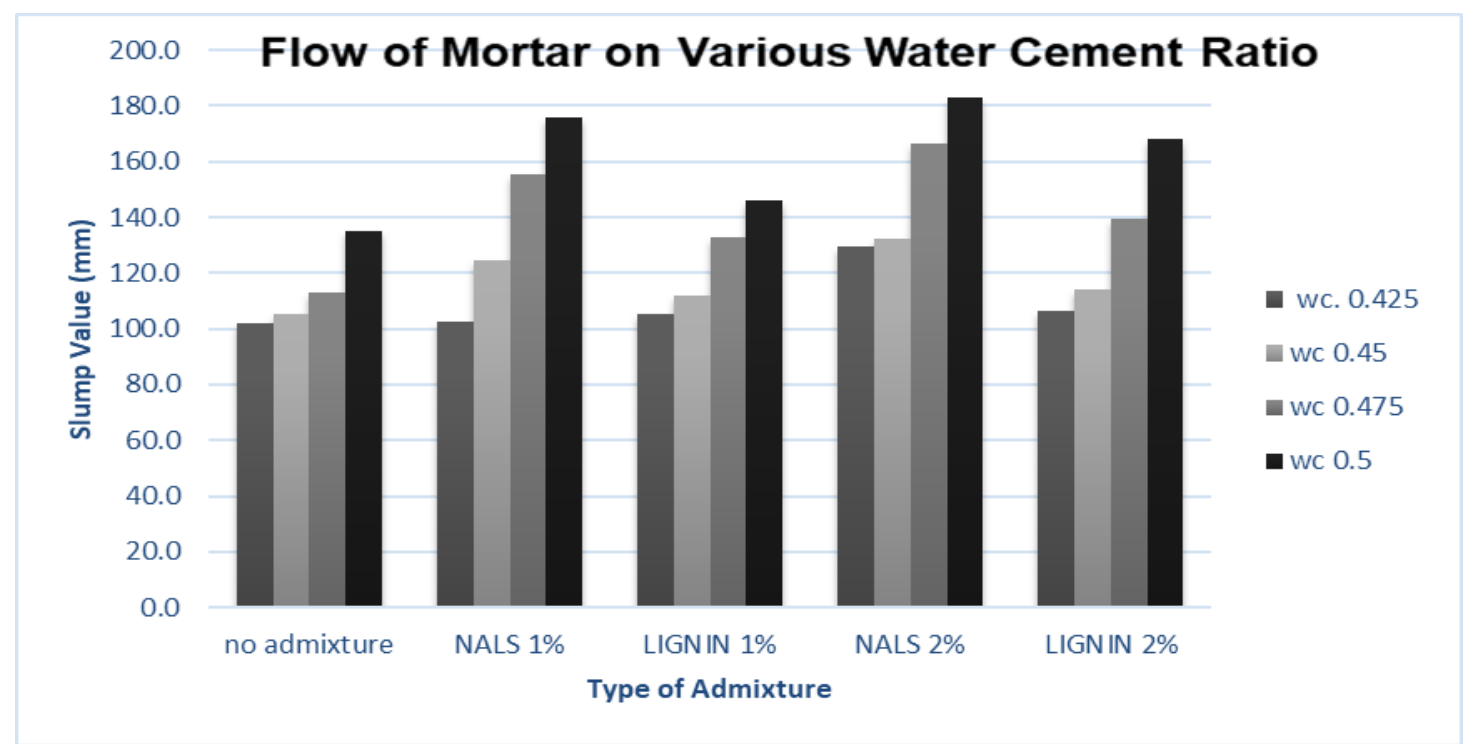

Figure 3. Effect of additives on slump value.

\section{Effect of Additives on Compression Strength}

The addition of admixture in the mortar ages 7 and 28 days did not significantly differ in mortar density. Mortar densities remained approximately $2 \mathrm{mg} / \mathrm{mm}^{3}$ on various water-cement ratios and variations in the admixture. Figure 4 showed that the compressive strength of mortar using lignin OPEFB fibers greater than in the control and commercial NaLS either on the addition of $1 \%$ or $2 \%$ at $\mathrm{W} / \mathrm{C} 0.425$. The use of lignin from OPEFB fibers in the concrete resulted in the best compressive strengths in different water-cement ratio values than controls and NaLS with the highest compressive strength value at W/C of 0.425 with the addition of $2 \%$ lignin of $32.45 \mathrm{~N} / \mathrm{mm}^{2}$ compressive strength. Referred to Concrete Work Guidelines for Roads and Bridges, the value of compressive strength of mortar in concrete was classified as qualify for use as a mortar to mix like a slab of reinforced concrete bridges, reinforced concrete girder, diaphragm, curbs, precast concrete, culvert reinforced concrete, and for building the bridge. The compressive strength is also better than the compressive strength of mortar added with synthetic NaLS at the age of 7 days, on average reached a value of approximately $26 \mathrm{~N} / \mathrm{mm}^{2}$. However, at $\mathrm{W} / \mathrm{C}$ of 0.50 , only mortar enriched with $1 \%$ lignin was better than controls, although the use of lignin as an admixture in mortar still produced a higher compressive strength than the use of commercial NaLS. The higher compressive strength of mortar with NaLS reached in the addition of $1 \%$, indicating that increasing of NaLS decrease the compressive strength on various water-cement ratio. The more NaLS are added, the nature of sulfonate groups hidrophility increased and resulted in larger the voids between cement particles and lead to void space so that the distance between the particles becomes larger and the bond becomes weaker, causing lower compressive strength (Zheng et al. 2018). This is not the case in the addition of lignin as an additive that increases its strength. The addition of lignin OPEFB fibers speeds up the hardening time (setting time) so that the maximum compressive strength of mortar produced reached by sooner. 


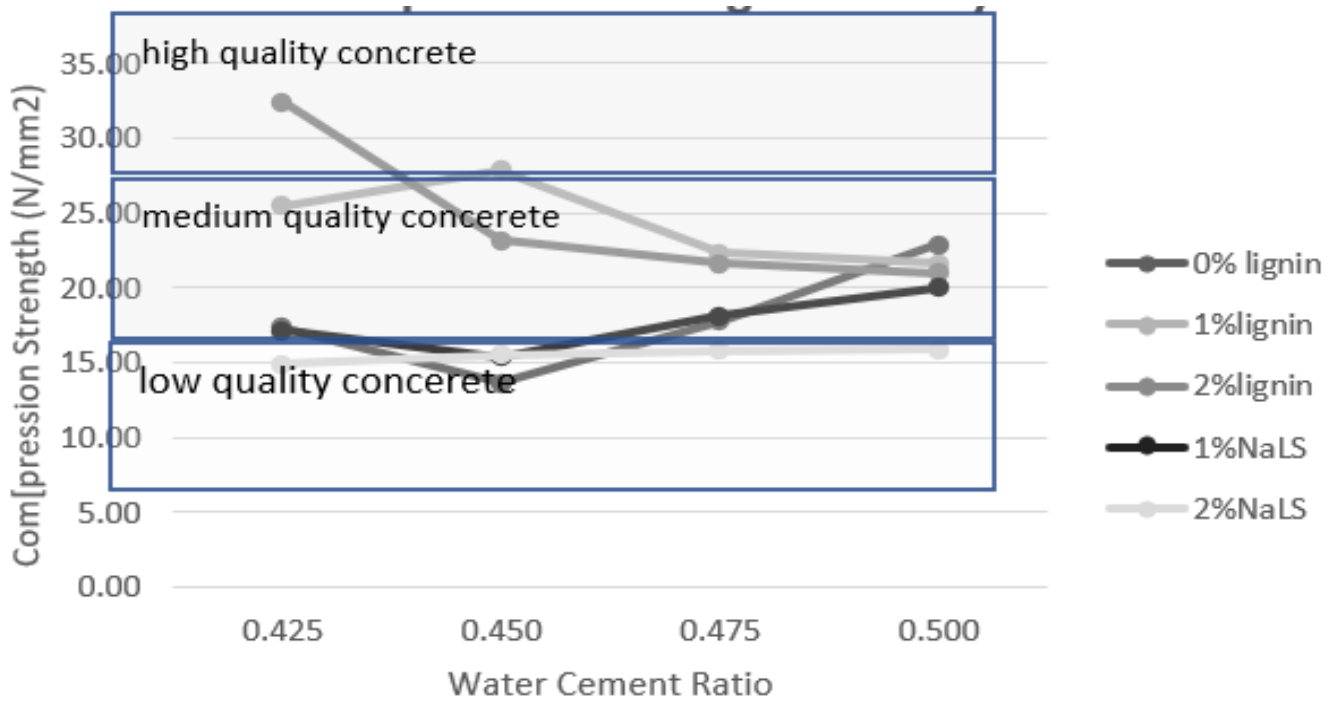

Figure 4. Effect of additives on compression strength at 7 days.

The increase of the water-cement ratio generally contributed to the decline in the compressive strength of mortar control. However, it was in contrast to the behavior of mortar added with NaLS and lignin. The compressive strength of mortar produced by the addition of lignin at 28 days remained higher than those with the addition of NaLS. At W/C of 0.5 , the compressive strength of mortar with NaLS $1 \%$ is slightly higher than the compressive strength of NaLS $2 \%$. Addition of $1 \%$ lignin resulting in the greatest compressive strength at $0.45 \mathrm{~W} / \mathrm{C}$. Figure 5 shows that the use of $\mathrm{W} / \mathrm{C}$ more than 0.45 may result in a smaller compressive strength than the compressive strength generated by the W/C 0.45 .

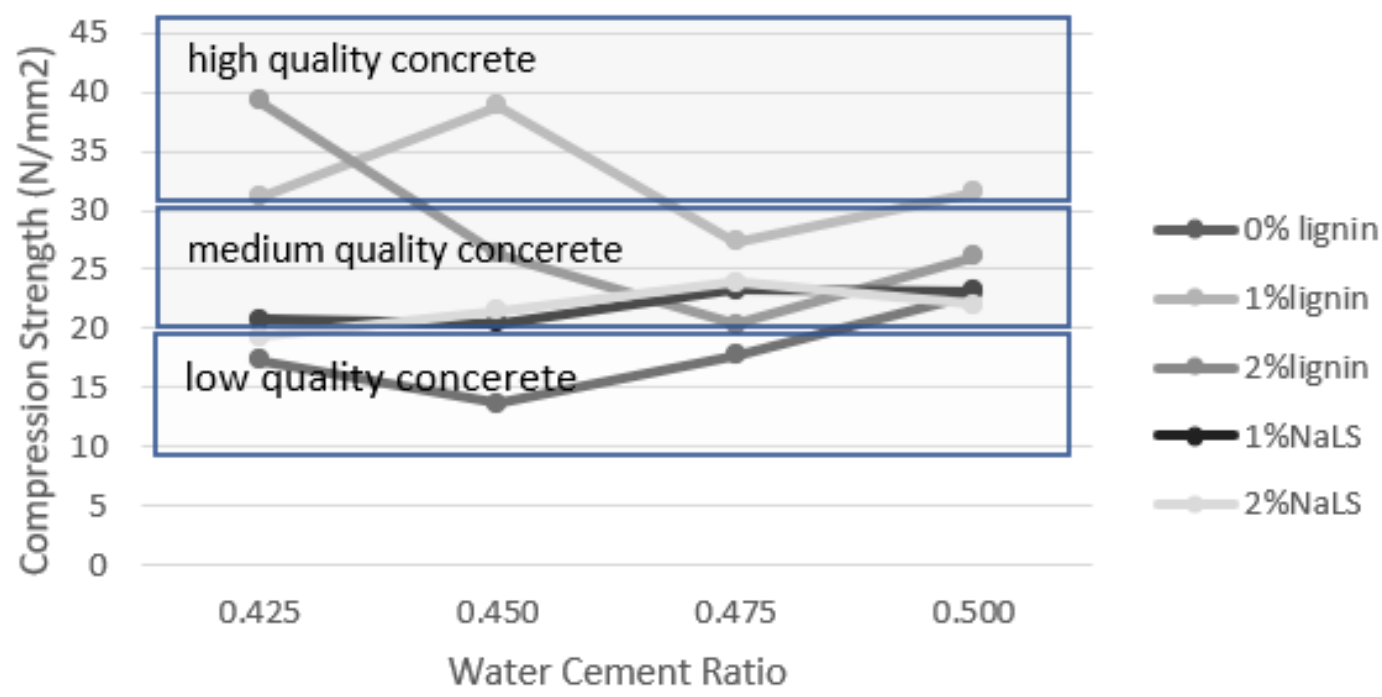

Figure 5. Effect of additives on compression strength at 28 days.

The use of lignin from OPEFB fibers in the mortar producing the best compressive strength at the age of 28 days in various $\mathrm{W} / \mathrm{C}$ ratio when compared with controls and NaLS with the highest compressive strength value was at $\mathrm{W} / \mathrm{C}$ of 0.425 with the addition of $2 \%$ lignin that is $39.28 \mathrm{~N} / \mathrm{mm}^{2}$. The value of compressive strength of mortar is classified in the appropriate quality concrete Cleaner Concrete Work Guidelines for Roads and Bridges that qualify for use as a mortar for prestressed concrete mixtures such as prestressed concrete piles, prestressed concrete girder, prestressed concrete slab, and the like. At 28 days, the compressive strength of mortar with lignin obtained from OPEFB was better than those with NaLS additive, which 
according to Nadif et al. (2002) reaches a value below $30 \mathrm{~N} / \mathrm{mm}^{2}$. The addition of lignin in the mortar mixture could cause stronger bonding between the particles of cement, thus increasing its compressive strength. However, the addition of $2 \%$ lignin only provides excellent compressive strength at W/C of 0.425 . Increased of water would lead to the reduction of mortar compressive strength.

\section{Effect of mortar age on Compression strength}

Figure 6 shows that the compressive strength of mortar at W/C of 0.425 at the age of 7 days resulted in greater strength with the use of additives either NaLS or Lignin compared to compressive strength at the age of 28 days. This suggests that the time required to harden the mortar with the addition of NaLS and Lignin is shorter than the controls at the age of 7 days, which is still below $60 \%$ strength than compressive strength at 28 days. The results indicated that after 14 days, mortar with the addition of lignin and NaLS did not show a more significant increase in their compressive strength, where it only increased less than $10 \%$. It shows that at 14 days, mortar compressive strength is estimated to have reached the maximum strength.

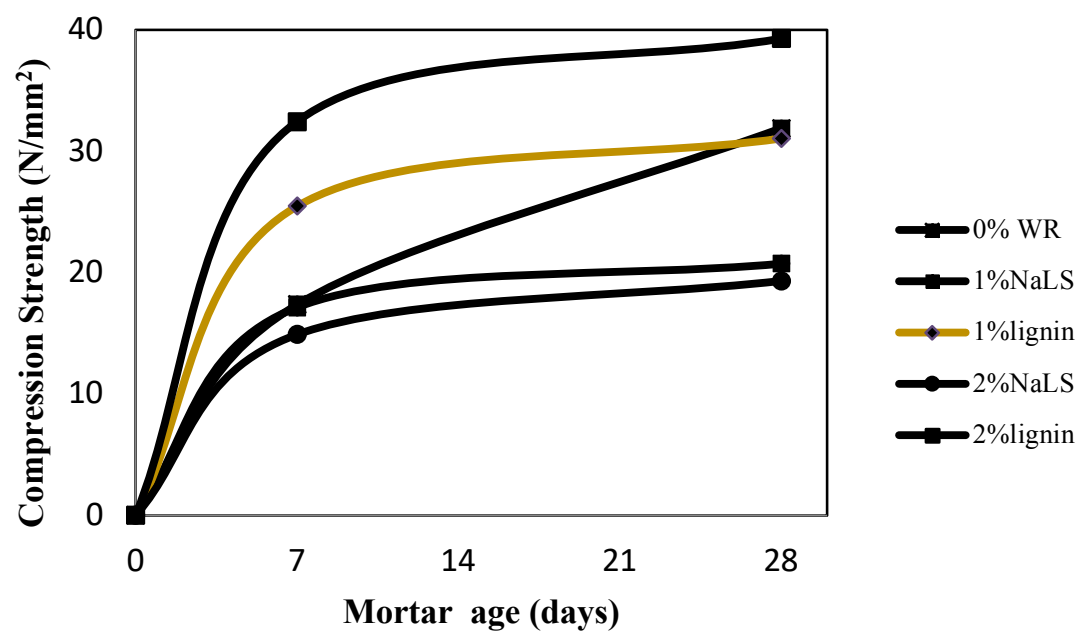

Figure 6. Effect of mortar age on compression strength at 0.425 water-cement ratio.

Figure 7 shows that the compressive strength of mortar at W/C of 0.45 at the age of 7 days with lignin-based additives produces higher compressive strength than the controls.

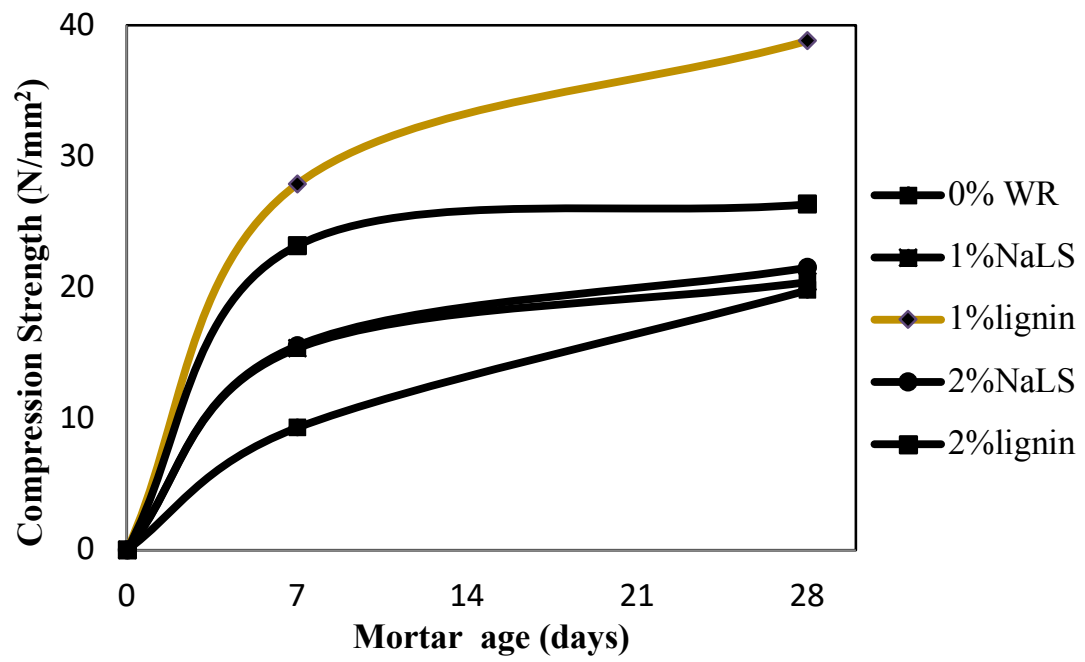

Figure 7. Effect of mortar age on compression strength at 0.45 water-cement ratio. 
The compressive strength of mortar with additives at the age of 7 days was more than $70 \%$ compared to its strength at 28 days, even on a mortar with $2 \%$ lignin the compressive strength reached $88 \%$ at the age of 28 days. This suggests that the time required to harden the mortar with the addition of NaLS and Lignin was shorter than the controls at the age of 7 days, which is still below $50 \%$ strength than its compressive strength at 28 days. Nevertheless, the mortar at $\mathrm{W} / \mathrm{C}$ of 0.45 shows that the addition of $1 \%$ lignin produces a higher compressive strength than that of mortar with $2 \%$ lignin. This suggests that the increase of lignin concentration at $\mathrm{W} / \mathrm{C}$ of 0.45 resulting in the reduction of the mortar compressive strength. The results revealed that after 14 days mortar with the addition of lignin and NaLS did not show a significant increment in its compressive strength. It showed that at 14 days, mortar compressive strength is estimated to have reached the maximum.

Figure 8 shows that the compressive strength of mortar at W/C of 0.475 showed an increase in compressive strength at the age of 7 days, either with and without additives. Mortar control and mortar with a $2 \%$ of NaLS showed that its compressive strength had reached 66$68 \%$ of its strength at 28 days, while the mortar with $1 \%$ lignin and $1 \%$ NaLS reached $88 \%$ of its 28 days strengths. Mortar with $2 \%$ lignin even shows the maximum compressive strength at the age of 7 days. This suggests that the addition of lignin as much as $2 \%$ in mortar can accelerate the hardening time of mortar so that at the age of 7 days it hardened perfectly.

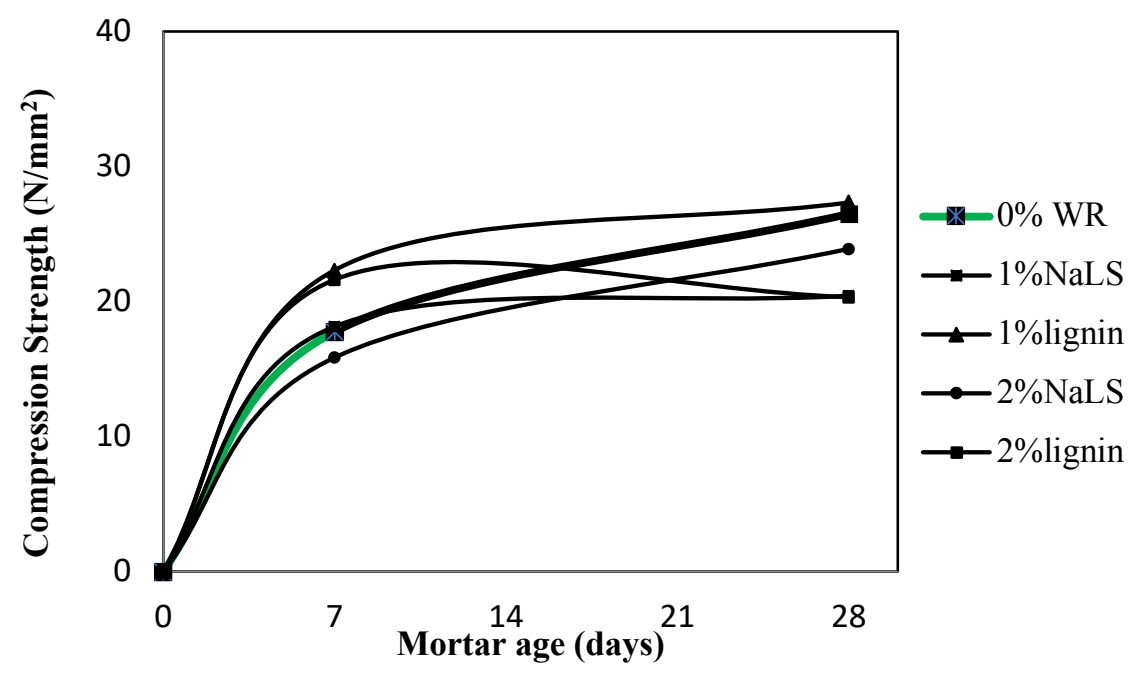

Figure 8. Effect of mortar age on compression strength at 0.475 water-cement ratio.

Figure 9 shows that the compressive strength of mortar at W/C of 0.5 was slightly better with additives that reached $90 \%$ of its strength at the age of 7 days compared to the strength of mortar with additives, which only reached less than $90 \%$ than its strength at 28 days. This suggests that the increase of water slowing the hardening of mortar with additives. From this study it can be concluded that the mortar with additives should be produced with W/C less than 0.5 , resulting in a shorter hardening time. The best compressive strength with a short hardening time was obtained with an additional $2 \%$ lignin in the W/C 0.425 , where $32.45 \mathrm{~N} / \mathrm{mm}^{2}$ compressive strength reached at the age of 7 days and $39.28 \mathrm{~N} / \mathrm{mm}^{2}$ mortar at the age of 28 days. However, if mortar with qualified slump value and high compressive strength is desired, it requires the addition of $1 \%$ lignin in a mortar with $0.45 \mathrm{~W} / \mathrm{C}$ that produces mortar with a slump value of $112 \mathrm{~mm}$ where a 7 days compressive strength reaches $27.88 \mathrm{~N} / \mathrm{mm}^{2}$ and 38.81 $\mathrm{N} / \mathrm{mm}^{2}$ mortar at the age of 28 days. 


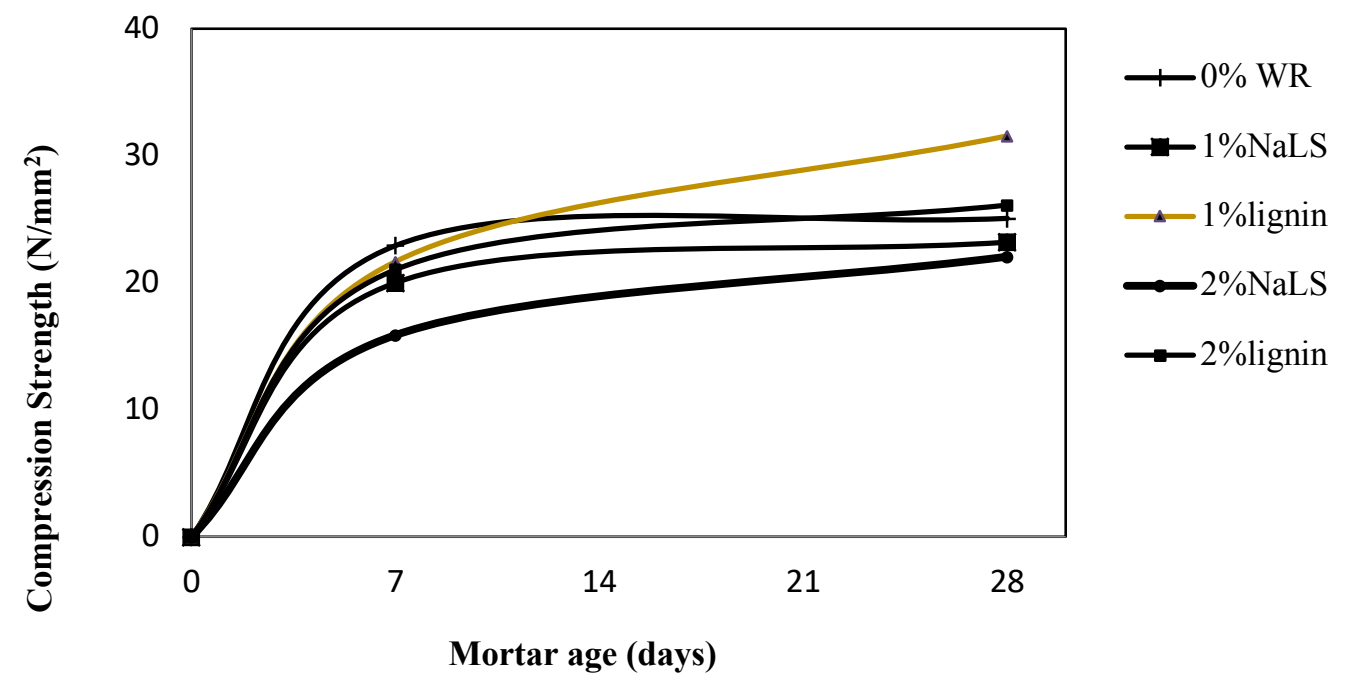

Figure 9. Effect of mortar age on compression strength at 0.50 water-cement ratio.

\section{CONCLUSIONS}

Lignin from OPEFB fibers used for bioethanol production can be used as a water reducer in mortar. The workability of the mortar with lignin OPEFB fibers additive increased to $24.4 \%$ (at W/C of 0.5) compared to the controls, although lower than the NaLS workability where the increase reached to $47.0 \%$ compared to the control (at W/C of 0.475 ). The addition of lignin from OPEFB fibers increased the compressive strength of mortar at the age of 7 and 28 days compared to the addition of NaLS at various water-cement ratio with the highest compressive strength of $39.28 \mathrm{~N} / \mathrm{mm}^{2}$ achieved on the addition of $2 \%$ lignin and the water-cement ratio of 0.425 . The hardening time of mortar with lignin additives increases rapidly so that the required curing time is shorter. At the age of 7 days, the mortar's compressive strength has reached up to $80 \%$ of compressive strength at the age of 28 days. The highest increment in compressive strength with good slump value of mortar obtained on the addition of $1 \%$ lignin and the watercement ratio of 0.45 with a slump value of $112 \mathrm{~mm}$ resulting in compressive strength of 27.88 $\mathrm{N} / \mathrm{mm}^{2}$ and $38.81 \mathrm{~N} / \mathrm{mm}^{2}$ at the age of 7 days and 28 days, respectively.

\section{ACKNOWLEDGMENTS}

The authors would like to thank the Research Center for Biomaterials LIPI and Integrated Laboratory of Bioproducts (iLaB) for their support and process equipment.

\section{REFERENCES}

Angelini, S., Barrio, A., Cerruti, P., Scarinzi, G., Garcia-Jaca, J., Savy, D., Piccolo, A., and Malinconico, M. 2019. Lignosulfonates as fire retardants in wood flour-based particleboards. International Journal of Polymer Science 2019: 6178163. DOI: $10.1155 / 2019 / 6178163$

Aro, T., and Fatehi, P. 2017. Production and Application of Lignosulfonates and Sulfonated Lignin. ChemSusChem 10(9): 1861-1877. DOI: 10.1002/cssc.201700082

BSN. 1990. SNI 03-1974-1990 Metode Pengujian Kuat Tekan Beton. Jakarta, Indonesia 1-17. Childs, C. M., Perkins, K. M., Menon, A., and Washburn, N. R. 2019. Interplay of Anionic 
Functionality in Polymer-Grafted Lignin Superplasticizers for Portland Cement. Industrial and Engineering Chemistry Research research-article, American Chemical Society 58(43): 19760-19766. DOI: 10.1021/acs.iecr.9b03973

Dessbesell, L., Paleologou, M., Leitch, M., Pulkki, R., and Xu, C. 2020. Global Lignin Supply Overview and Kraft Lignin Potential as an Alternative for Petroleum-Based Polymers. Renewable and Sustainable Energy Reviews 123: 109768. DOI: 10.1016/j.rser.2020.109768

FAO. 2019. Forest Products Annual Market Review, 2018-2019. United Nations Economic Commission for Europe (UNECE). Geneva, Switzerland. DOI: 10.1017/CBO9781107415324.004

Gupta, C., Nadelman, E., Washburn, N. R., and Kurtis, K. E. 2017. Lignopolymer Superplasticizers for Low-CO2 Cements. ACS Sustainable Chemistry and Engineering 5(5): 4041-4049. DOI: 10.1021/acssuschemeng.7b00021

Hemmilä, V., Adamopoulos, S., Hosseinpourpia, R., and Ahmed, S. A. 2019. Ammonium Lignosulfonate Adhesives for Particleboards with pMDI and Furfuryl Alcohol as Crosslinkers. Polymers 11(10): 1633. DOI: 10.3390/polym11101633

Hermiati, E., Risanto, L., Lubis, M. A. R., Laksana, R. P. B., and Dewi, A. R. 2017. Chemical Characterization of Lignin from Kraft Pulping Black Liquor of Acacia mangium. in: AIP Conference Proceedings. DOI: 10.1063/1.4973132

Jankowska, D., Heck, T., Schubert, M., Yerlikaya, A., Weymuth, C., Rentsch, D., Schober, I., and Richter, M. 2018. Enzymatic Synthesis of Lignin-Based Concrete Dispersing Agents. ChemBioChem 19(13): 1365-1369. DOI: 10.1002/cbic.201800064

Kalliola, A., Vehmas, T., Liitiä, T., and Tamminen, T. 2015. Alkali-O2 Oxidized Lignin - A Bio-Based Concrete Plasticizer. Industrial Crops and Products 74: 150-157. DOI: 10.1016/j.indcrop.2015.04.056

Lin, F., and Meyer, C. 2009. Hydration Kinetics Modeling of Portland Cement Considering the Effects of Curing Temperature and Applied Pressure. Cement and Concrete Research 39(4): 255-265. DOI: 10.1016/j.cemconres.2009.01.014

Nadif, A., Hunkeler, D., and Käuper, P. 2002. Sulfur-Free Lignins from Alkaline Pulping Tested in Mortar for Use as Mortar Additives. Bioresource Technology 84(1): 49-55. DOI: 10.1016/S0960-8524(02)00020-2

Natarelli, C. V. L., Lemos, A. C. C., de Assis, M. R., Tonoli, G. H. D., Trugilho, P. F., Marconcini, J. M., and de Oliveira, J. E. 2019. Sulfonated Kraft Lignin Addition in UreaFormaldehyde Resin: Thermokinetic Analysis. Journal of Thermal Analysis and Calorimetry 137(5): 1537-1547. DOI: 10.1007/s10973-019-08075-1

Sudiyani, Y., Styarini, D., Triwahyuni, E., Sudiyarmanto, Sembiring, K. C., Aristiawan, Y., Abimanyu, H., and Han, M. H. 2013. Utilization of Biomass Waste Empty Fruit Bunch Fiber of Palm Oil for Bioethanol Production using Pilot - Scale Unit. Energy Procedia 32: 31-38. DOI: 10.1016/j.egypro.2013.05.005

Takahashi, S., Hattori, M., Morimoto, M., Uraki, Y., and Yamada, T. 2014. Performance of Softwood Soda-Anthraquinone Lignin As Water-Reducing Chemical Admixture in Concrete. Journal of Wood Chemistry and Technology 34(1): 31-38. DOI: $10.1080 / 02773813.2013 .820322$

TAPPI. 1999. T $203 \mathrm{~cm}-99$. Alpha-, beta- and gamma-cellulose in pulp. TAPPI.

TAPPI. 2002. T 222 om-02. Acid-insoluble lignin in wood and pulp. TAPPI.

Thaker, P., and Arora, N. K. 2015. Selection of Test Method to Quantify Workability of Cement Paste and Mortar for Very Low Workable to High Workable Mix. International Journal of Engineering Sciences \& Research Technology 4(12): 854-860.

Tribot, A., Amer, G., Alio, M. A., Baynast, H. De, Delattre, C., Pons, A., Mathias, J., Callois, J., Vial, C., and Michaud, P. 2019. Wood-Lignin : Supply, Extraction Processes and Use 
as Bio-Based Material. European Polymer Journal 112: 228-240. DOI: 10.1016/j.eurpolymj.2019.01.007

Wang, H., Pu, Y., Ragauskas, A., and Yang, B. 2019. From Lignin to Valuable ProductsStrategies, Shallenges, and Prospects. Bioresource Technology. DOI: 10.1016/j.biortech.2018.09.072

Windeisen, E., and Wegener, G. 2012. Lignin as Building Unit for Polymers. Polymer Science: A Comprehensive Reference, 10 Volume Set Elsevier B.V. DOI: 10.1016/B978-0-44453349-4.00263-6

Yang, S., Zhang, Y., Yuan, T. Q., and Sun, R. C. 2015. Lignin-Phenol-Formaldehyde Resin Adhesives Prepared with Biorefinery Technical Lignins. Journal of Applied Polymer Science 132(36): 1-8. DOI: 10.1002/app.42493

Zhang, W., Ma, Y., Wang, C., Li, S., Zhang, M., and Chu, F. 2013. Preparation and Properties of Lignin-Phenol-Formaldehyde Resins Based on Different Biorefinery Residues of Agricultural Biomass. Industrial Crops and Products 43: 326-333. DOI: 10.1016/j.indcrop.2012.07.037

Zheng, D., Zheng, T., Chen, R., Li, X., and Qiu, X. 2018. Amination of Black Liquor and the Application in the Ready-Mixed Wet Mortar. Environmental Technology 39(1): 44-50. DOI: $10.1080 / 09593330.2017 .1294622$ 